\title{
A Positive Learning Spiral of Skill Development in High-Risk Recre- ation: Reversal Theory and Flow
}

Susan Pfab Houge, Ken Hodge, and Mike Boyes

his research project investigated the motivational basis of skill development in high risk recreation. Flow Theory (e.g., Csikszentmihalyi, 1975; Nakamura \& Csikszentmihalyi, 2005) and Reversal Theory (RT, e.g., Apter, 1982, 2001) are two general psychological models which describe the structure of motivation and offer theoretical bases from which to understand both optimal experiences (e.g., flow) and nonoptimal experiences (e.g., fear and anxiety) in high risk recreation. Reversal Theory is grounded in the tenet that individuals regularly reverse between opposing metamotivational states (e.g., between the "telic" seriousminded state and the "paratelic" playful state) and that the quality of current experience is dictated by an individual's metamotivational state at any given time (e.g., Frey, 1999; Potocky \& Murgatroyd, 1993). Flow research with adolescents has demonstrated that a synergy between momentary involvement (i.e., flow) and long-term goals can optimise talent development (Csikszentmihalyi, Rathunde, \& Whalen, 1993). Theoretical literature has proposed that an integration of key constructs in these theories could better elucidate optimal experiences and their relation to a “positive learning spiral” of skill development (Rea, 1993). Specifically, a balance of serious and playful states, and flow states, has been postulated to optimise skill development over time (Rea, 1993). Despite theoretical similarities, previous research has not empirically evaluated the nature of high risk recreation flow states, or their role in a positive learning spiral, within a Reversal Theory framework. Therefore this study evaluated: (a) whether a "positive learning spiral" of skill development was evident 
in high risk recreation, (b) the nature of flow states in relation to a "positive learning spiral," and (c) whether a "positive learning spiral" was related to the development of increasingly complex flow states (e.g., serious play), as suggested by theoretical literature.

\section{Methodology}

This study employed a prospective, mixed-methods design (Creswell, 2002) to investigate the nature of flow and a positive learning spiral of skill development amongst novice riversurfers (a high risk recreation activity in which participants navigate and surf river rapids on a body board) during a three day riversurfing course. Novices were purposefully selected to evaluate key constructs during initial skill development phases (Patton, 2002), while riversurfing was selected as this activity was expected to facilitate flow based on criteria identified in flow literature (e.g., clear goals; quick/automatically reactions required; opportunities to continually rebalance challenges and skills; Jackson \& Csikszentmihalyi, 1999). Moreover, previous investigations of flow in whitewater settings documented flow and dramatic mood changes pre and postrapids (e.g., Jones, Hollenhorst, \& Perna, 2003; Jones, Hollenhorst, Perna, \& Selin, 2000; Males, 1999; Males \& Kerr, 1996; Priest \& Bunting, 1993).

Quantitative data was collected with all 10 course participants (mean age $=23 \mathrm{yrs}, 8$ males, 2 females) via survey measures related to RT states (i.e., the telic/paratelic state instrument, T/PSI, O'Connell \& Calhoun, 2001), flow states (i.e., the Short Flow State Scale, SFSS, Martin \& Jackson, 2008) and perceptions of challenges and skills (Stavrou, Jackson, Zervas, \& Karterliotis, 2007) at key points throughout these three days. In addition, five of these ten participants (mean age $=25 \mathrm{yrs}, 3$ males, 2 females) were purposefully selected to wear head-mounted video cameras throughout the course and participate in daily interviews facilitated by footage from their camera. These five participants were purposefully selected to provide a cross-section of outdoor and whitewater experience (e.g., more to less experienced) as previous research indicated that experience in one domain could influence an individual's experience in similar environments (i.e., previous river experience) and/or utilising similar skill sets (e.g., Brody, Hatfield, \& Spalding, 1988; Creyer, Ross, \& Evers, 2003; Ewert \& Hollenhorst, 1989). Therefore, daily interviews of between 25 to 50 minutes were conducted in a semistructured, inductive format which concluded with deductive concepts (Patton, 2002; Scanlan, Russell, Wilson, \& Scanlan, 2003). Data was analysed using a concurrent nested design process (Creswell, Plano Clark, Gutmann, \& Hanson, 2003) in which quantitative and qualitative data are interpreted concurrently, but quantitative findings are "nested" within, or considered as supplementary to, qualitative data analysis. 


\section{Results}

Quantitative data regarding flow and RT states, and perceived challenge and skill ratings were triangulated with qualitative interview data to identify key trends and qualitative differences amongst flow states. Both of these data sets demonstrated that participants experienced high levels of flow and regular metamotivational reversals throughout the three day riversurfing course. Data also supported the constructs of telic flow, paratelic flow and the positive learning spiral. Specifically, telic and paratelic flow states appeared to differ qualitatively based on the degree of salience of key aspects of these states (e.g., level of goal importance, arousal-seeking). In the telic state, anxiety and potentially unpleasant feelings regarding challenges and goal achievement tended to precede more "intense" flow experiences, while the paratelic state appeared to provide a wider range of flow opportunities as paratelic flow did not appear as outcome dependent as telic flow. Higher skill perceptions (e.g., sense of control) and the presence of clear, challenging goals also appeared to be a more important antecedent of telic flow than paratelic flow. The finding that telic flow tended to occur the first time participants mastered a novel task, while paratelic flow was more likely to occur once a task became familiar or "automatic," also suggested a multi-phasic relationship between these flow states and a positive learning spiral of development. Data suggested that the dynamic recalibration of perceived challenges and skills which was necessary to facilitate these distinct flow states contributed to the multi-phasic nature of these states and a positive learning spiral skill development (in the longer term).

\section{Discussion}

This study provided a starting point from which to identify qualitative differences amongst states of flow and enjoyment, and their relation to a positive learning spiral of longer-term skill development, in high risk recreation. Contrary to previous theoretical RT literature (i.e., Apter, 1982; Kerr, 1989), the key role of the telic state in flow experiences was supported. Results suggested that telic and paratelic flow states, and resulting emotions (e.g., satisfaction, relaxation), in high risk recreation were dynamic and multi-phasic. Moreover, optimal experiences (in the short term) and skill development (in the longer-term) appeared to depend upon the dynamic tensions between opposing states (e.g., telic seriousness and paratelic playfulness; anxiety and excitement), rather than one state in isolation. Continually shifting perceptions of personal skills in relation to challenges also contributed to optimal alternation between telic and paratelic flow, and contributed to the upward movement of the positive learning spiral. 
These findings highlighted the symbiotic relationships amongst seemingly "opposing" states in the learning process and identified the need for further refinement of Flow Theory and Reversal Theory in the context of high risk recreation. These findings have practical implications for high risk recreation participants (e.g., mental skills training programs) and instructors with regard to the facilitation of optimal experiences in the short term (e.g., trip planning and activity sequencing) and optimal skill development in the longer-term (e.g., programme design). For example, alternating phases of perceived skill mastery and perceived skill learning can optimise skill development and enjoyment for participants. However, instructors should not necessarily eliminate all negative emotions as they appeared to function symbiotically with intense positive emotions. Instructors should seek to facilitate a range of flow opportunities at lower to moderate, as well as heightened perceived challenge levels.

Susan Houge is a Ph.D. student at University of Otago, Dunedin, New Zealand. E-mail: shouge2000@yahoo.com

Dr. Ken Hodge is an Associate Professor and Dr. Mike Boyes is a Senior Lecturer at the University of Otago, Dunedin, New Zealand.

\section{References}

Apter, M. J. (1982). The experience of motivation: The theory of psychological reversals. London: Academic Press.

Apter, M. J. (Ed.). (2001). Motivational styles in everyday life: A guide to Reversal Theory. Washington, DC: American Psychological Association.

Brody, E. B., Hatfield, B. D., \& Spalding, T. W. (1988). Generalization of self-efficacy to a continuum of stressors upon mastery of a high-risk sport skill. Journal of Sport and Exercise Psychology, 10, 32-44.

Creswell, J. W. (2002). Research design: Qualitative, quantitative, and mixed methods approaches (2nd ed.). Thousand Oaks, CA: Sage.

Creswell, J. W., Plano Clark, V. L., Gutmann, M. L., \& Hanson, W. E. (2003). Advanced mixed methods research designs. In A. Tashakkori \& C. Teddlie (Eds.), Handbook of mixed methods in social and behavioral research (pp. 209-240). Thousand Oaks: CA: Sage.

Creyer, E., Ross, W., \& Evers, D. (2003). Risky recreation: An exploration of factors influencing the likelihood of participation and the effects of experience. Leisure Studies, 22(3), 239-253.

Csikszentmihalyi, M. (1975). Beyond boredom and anxiety. San Francisco, CA: Jossey-Bass Publishers.

Csikszentmihalyi, M., Rathunde, K. R., \& Whalen, S. (1993). Talented teenagers: The roots of success and failure. New York: Cambridge University Press. 
Ewert, A., \& Hollenhorst, S. (1989). Testing the adventure model: Empirical support for a model of risk recreation participation. Journal of Leisure Research, 21(2), 124-139.

Frey, K. P. (1999). Reversal Theory: Basic concepts. In J. H. Kerr (Ed.), Experiencing sport: Reversal Theory (pp. 3-17). New York: John Wiley \& Sons.

Jackson, S. A., \& Csikszentmihalyi, M. (1999). Flow in sports. Champaign, IL: Human Kinetics.

Jones, C., Hollenhorst, S., \& Perna, F. (2003). An empirical comparison of the Four Channel Flow Model and Adventure Experience Paradigm. Leisure Sciences, 25(1), 17-31.

Jones, C., Hollenhorst, S., Perna, F., \& Selin, S. (2000). Validation of the Flow Theory in an on-site whitewater kayaking setting. Journal of Leisure Research, 32(2), 247-261.

Kerr, J. H. (1989). Anxiety, arousal, and sport performance: An application of Reversal Theory. In D. Hackfort \& C. D. Spielberger (Eds.), Anxiety in sports: An international perspective (pp. 137-151). New York: Hemisphere.

Males, J. (1999). Individual experience in slalom canoeing. In J. H. Kerr (Ed.), Experiencing sport: Reversal Theory (pp. 101-128). New York: John Wiley \& Sons.

Males, J., \& Kerr, J. H. (1996). Stress, emotion, and performance in elite slalom canoeists. The Sport Psychologist, 10, 17-36.

Martin, A. J., \& Jackson, S. A. (2008). Brief approaches to assessing task absorption and enhanced subjective experience: Examining 'short' and 'core' flow in diverse performance domains. Motivation and Emotion, 32(3), 141-157.

Nakamura, J., \& Csikszentmihalyi, M. (2005). The concept of flow. In C. R. Snyder \& S. J. Lopez (Eds.), Handbook of positive psychology (pp. 89-105). Oxford, UK: Oxford University Press.

O’Connell, K. A., \& Calhoun, J. E. (2001). The Telic/Paratelic State Instrument (T/PSI): Validating a Reversal Theory measure. Personality and Individual Differences, 30(2), 193-204.

Patton, M. Q. (2002). Qualitative research and evaluation methods (3rd ed.). London: Sage.

Potocky, M., \& Murgatroyd, S. (1993). What is Reversal Theory? In J. H. Kerr, S. J. Murgatroyd \& M. J. Apter (Eds.), Advances in Reversal Theory (pp. 13-26). Amsterdam: Swets \& Zeitlinger.

Priest, S., \& Bunting, C. (1993). Changes in perceived risk and competence during whitewater canoeing. Journal of Applied Recreation Research, 18(4), 265-280.

Rea, D. (1993). Reversal Theory explanations of optimal experience. In J. H. Kerr, S. J. Murgatroyd \& M. J. Apter (Eds.), Advances in Reversal Theory (pp. 75-88). Amsterdam: Swets \& Zeitlinger.

Scanlan, T. K., Russell, D. G., Wilson, N. C., \& Scanlan, L. A. (2003). Project on elite athlete commitment (PEAK): I. Introduction and methodology. Journal of Sport and Exercise Psychology, 25(3), 360-376.

Stavrou, N. A., Jackson, S. A., Zervas, Y., \& Karterliotis, K. (2007). Flow experience and athletes' performance with reference to the orthogonal model of flow. The Sport Psychologist, 21(4), 438-457. 